Supplement of

\title{
Sources of nitrous acid (HONO) in the upper boundary layer and lower free troposphere of North China Plain: insights from the Mount Tai Observatory
}

Ying Jiang ${ }^{1}$, Likun Xue ${ }^{1,4^{*}}$, Rongrong Gu${ }^{1}$, Mengwei Jia ${ }^{2}$, Yingnan Zhang ${ }^{1}$, Liang Wen ${ }^{1}$, Penggang Zheng ${ }^{1}$, Tianshu Chen ${ }^{1}$, Hongyong $\mathrm{Li}^{1}$, Ye Shan ${ }^{1}$, Yong Zhao ${ }^{3}$, Zhaoxin $\mathrm{Guo}^{3}$, Yujian $\mathrm{Bi}^{3}$, Hengde $\mathrm{Liu}^{3}$, Aijun Ding ${ }^{2,4}$, Qingzhu Zhang ${ }^{1}$, Wenxing Wang ${ }^{1}$

${ }^{1}$ Environment Research Institute, Shandong University, Qingdao, Shandong, 266237, China

${ }^{2}$ School of Atmospheric Sciences, Nanjing University, Nanjing, 210023, China

${ }^{3}$ Taishan National Reference Climatological Station, Tai'an, Shandong, 271000, China

${ }^{4}$ Collaborative innovation Center for climate Change, Jiangsu Province, Nanjing, 210023, China

*Correspondence to: Likun Xue (xuelikun@sdu.edu.cn) 


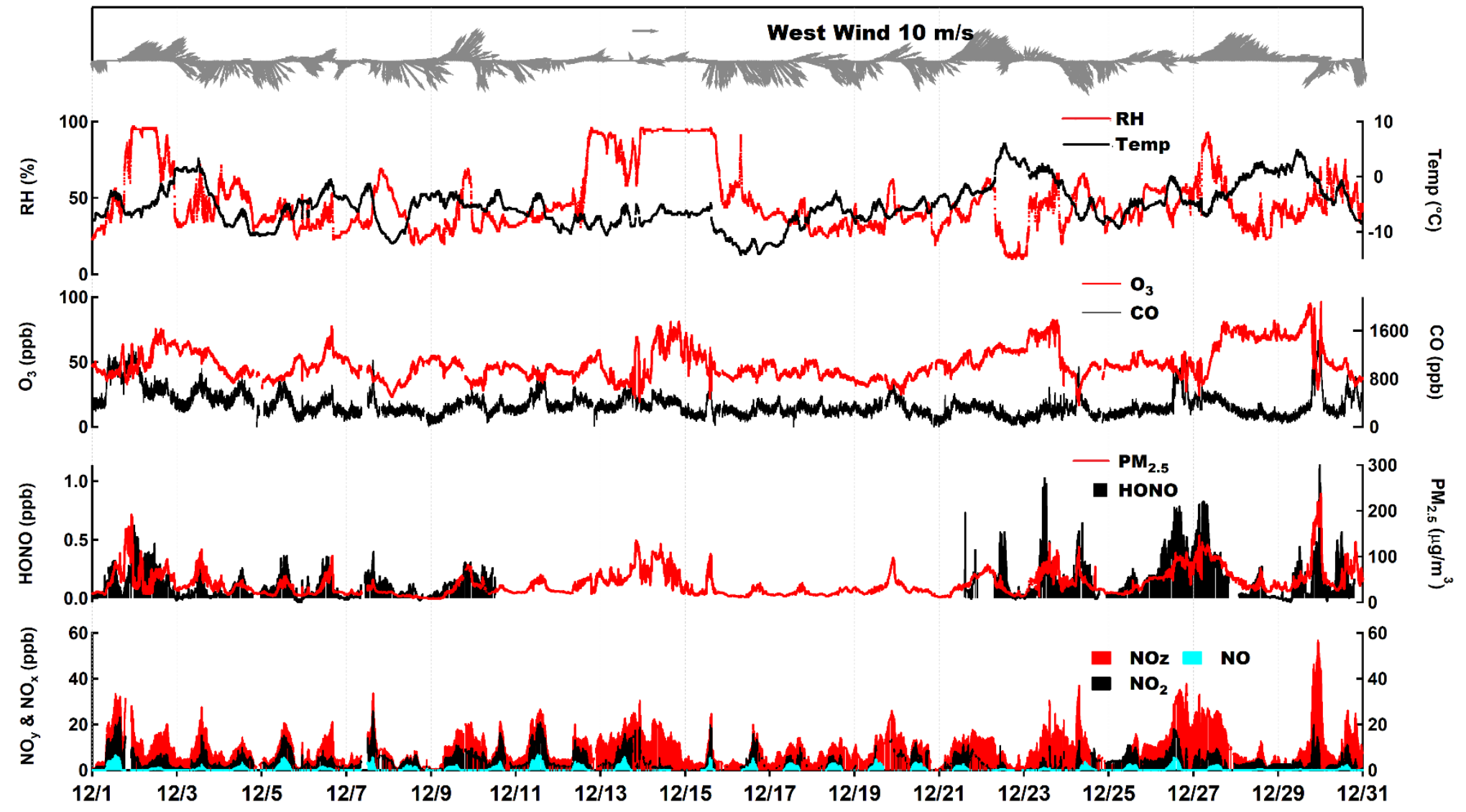

Figure S1. Time series of HONO and related parameters measured at Mt. Tai in winter 2017. The gap of measurement data was mainly due to the instrument failure and maintenance. 


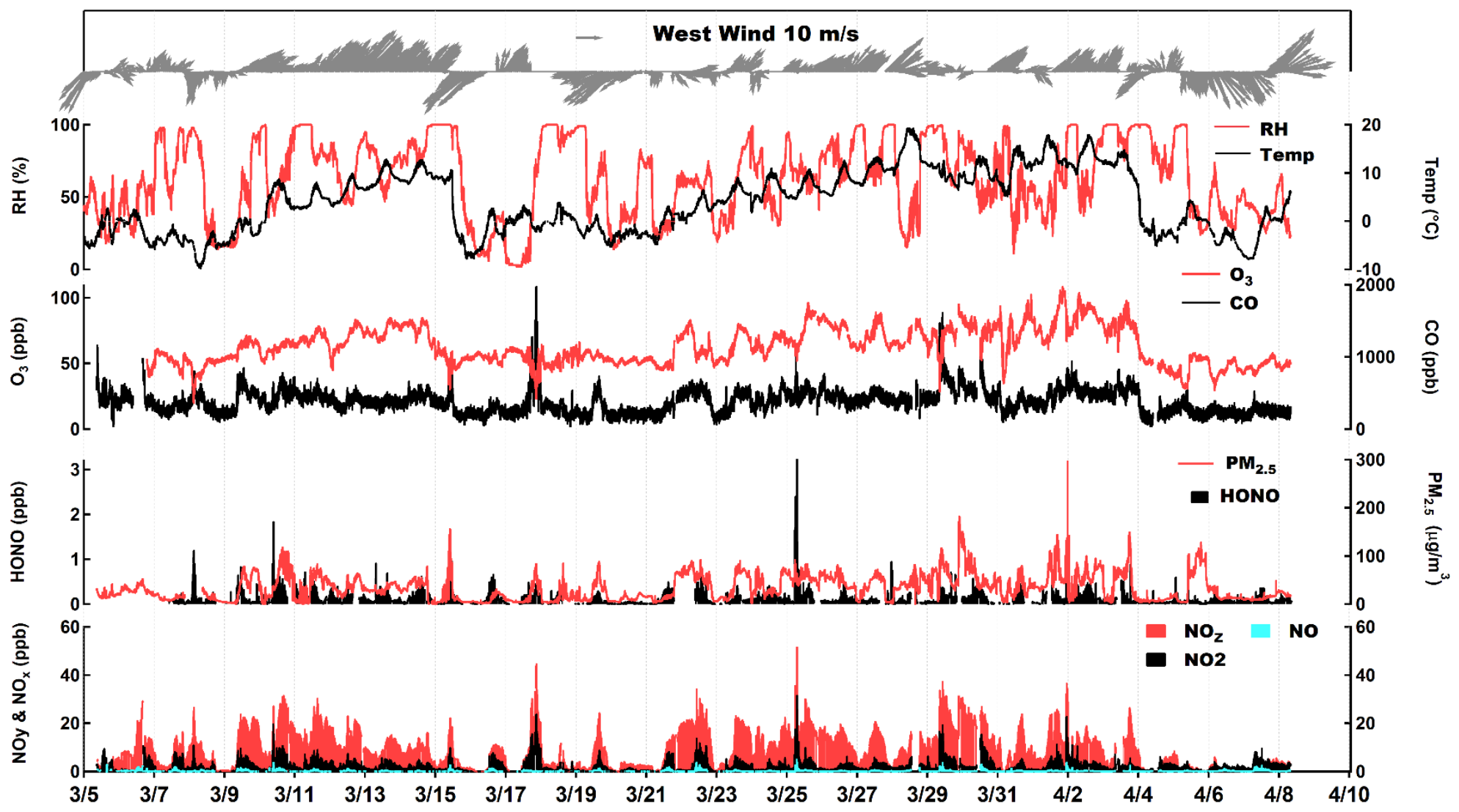

Figure S2. Time series of HONO and related parameters measured at Mt. Tai in spring 2018. The gap of data was mainly due to the instrument failure and maintenance. 

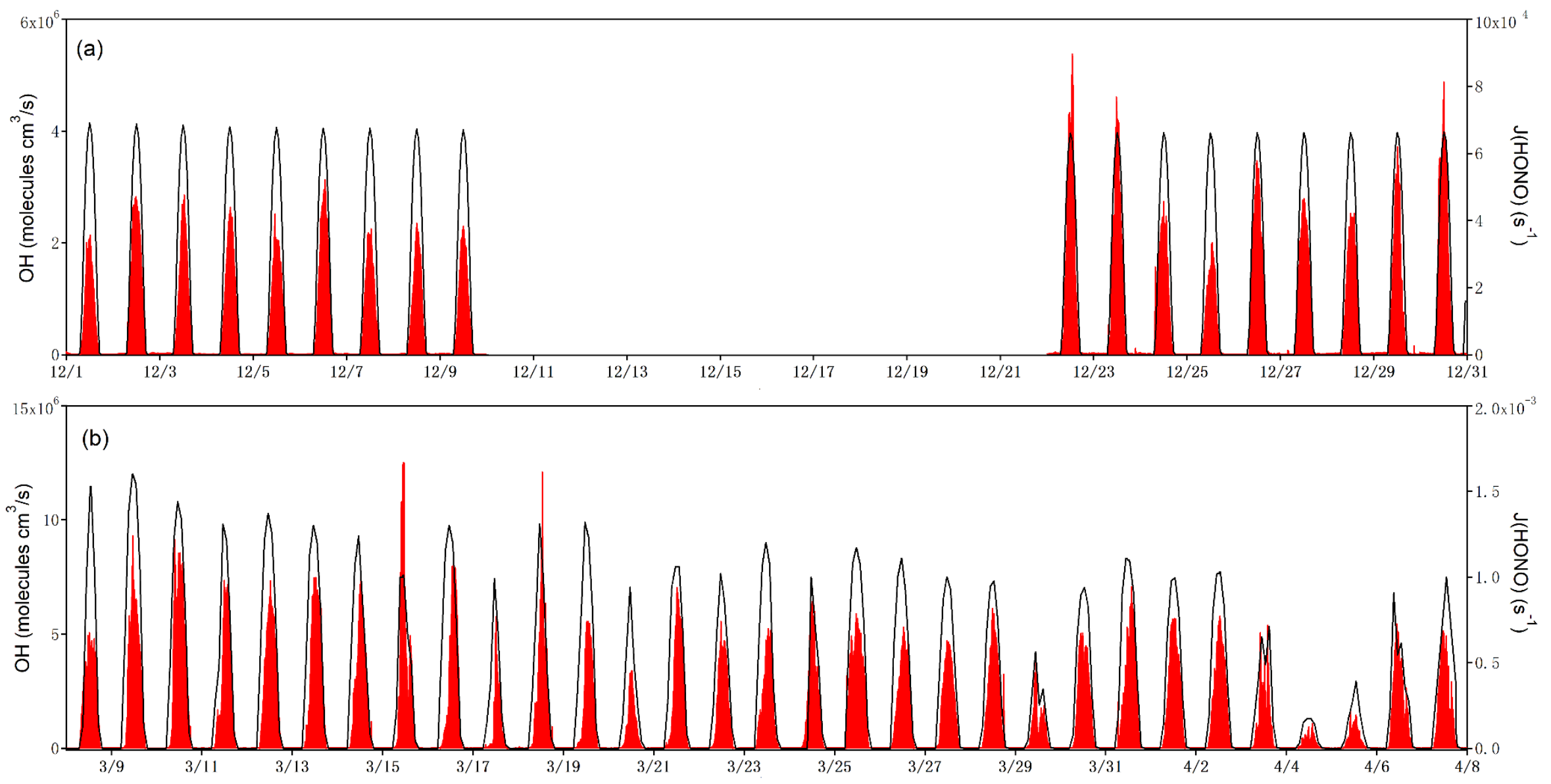

Figure S3. Time series of model-simulated OH concentrations (red) and measured-derived of $\mathrm{J}_{\text {HONO }}$ (black) at Mt. Tai in (a) winter 2017 and (b) spring 2018. 

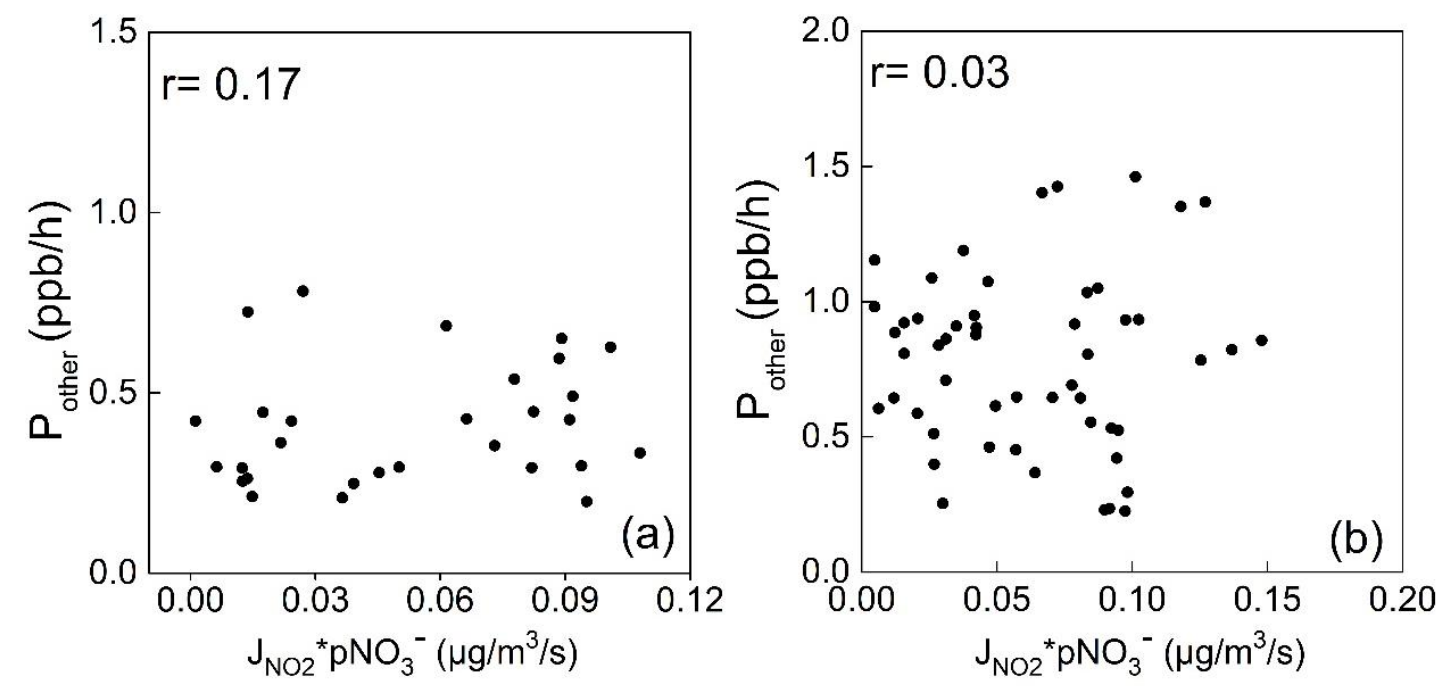

Figure S4. Scatter plots of the additional daytime HONO source strength $\left(\mathrm{P}_{\text {other }}\right)$ with $\mathrm{J}_{\mathrm{NO} 2} * \mathrm{pNO}_{3}{ }^{-}$in (a) winter 2017 and (b) spring 2018. 

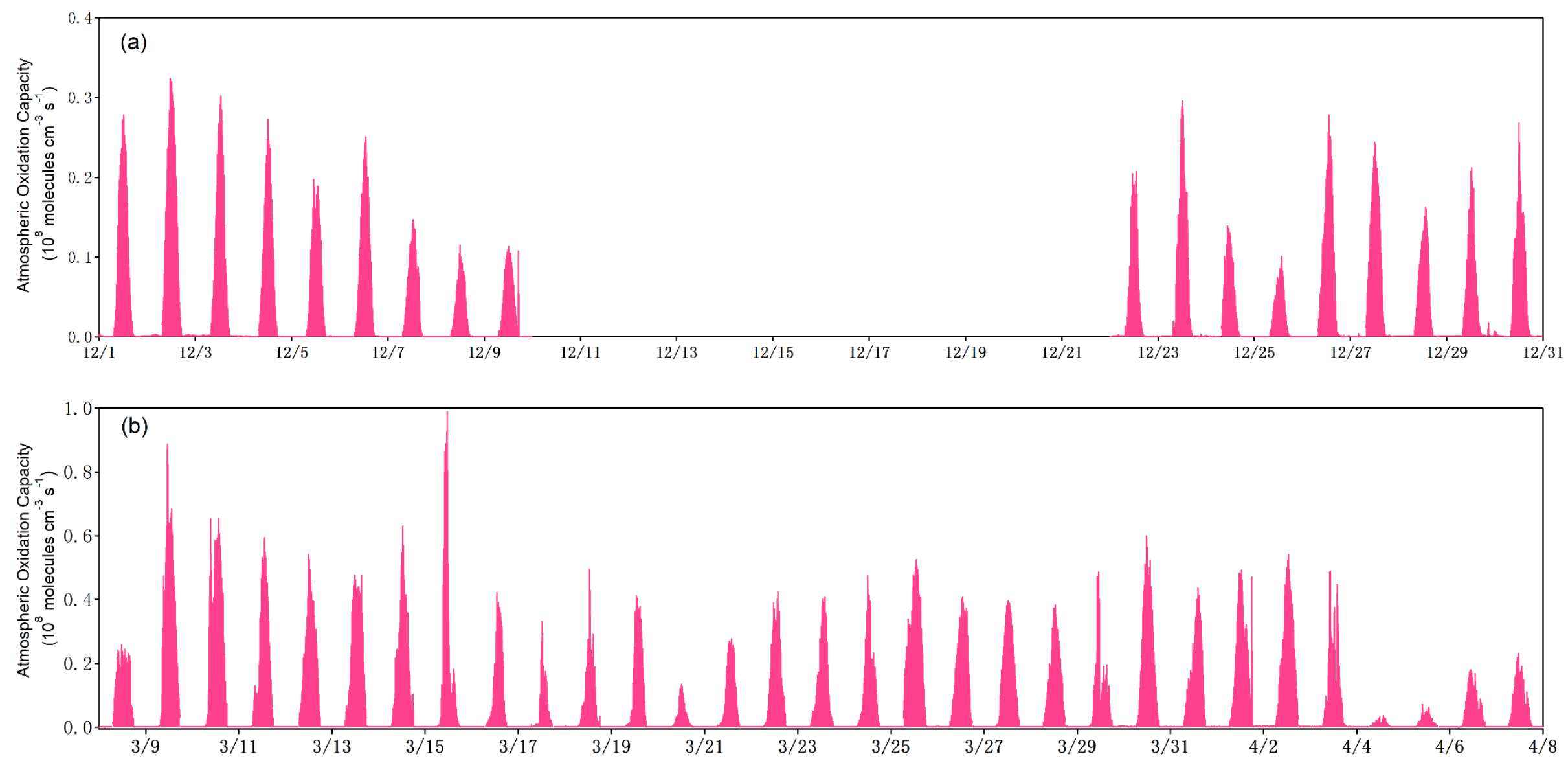

Figure S5. Model-simulated time series of atmospheric oxidation capacity (AOC) at Mt. Tai in (a) winter 2017 and (b) spring 2018. 